\title{
On the Effectiveness of a "Tractor Mounted Road Sanitizing Unit" Designed to Combat COVID-19 Spread
}

\author{
Dipankar Chatterjee $^{1}\left(\mathbb{D} \cdot\right.$ Samik Dutta $^{1} \cdot$ Bittagopal Mondal $^{1} \cdot$ Harish Hirani $^{1}$
}

Received: 30 July 2020/Accepted: 24 August 2020/Published online: 3 September 2020

(C) The Institution of Engineers (India) 2020

\begin{abstract}
Under the situation of a dreadful spread of COVID-19 throughout the world, it is an absolute necessity to develop proper strategy for its containment. Toward this end, a novel outdoor disinfection system is designed for effective sanitization of long stretches of highways, market places, shopping malls, etc., where there are large traffic and high chances of spreading of the virus. The disinfection system utilizes available tractor powered road tankers of municipal houses, and it has specific features for maximum sanitization coverage. This is achieved through a distributed spraying nozzle mounted around the tank along with two extendable hand sprayers with flexible hoses. The effectiveness of the spray system is studied using an image processing technique. The spray cloud is illuminated by a double-pulsed Nd:YAG laser, and the images are captured using a Nikon D3300 DSLR camera. The average droplet size of the spray coming out from the nozzle is measured, and finally, the area of influence of the spray is obtained from a statistical analysis.
\end{abstract}

Keywords COVID-19 • Outdoor disinfection system · Sanitization $\cdot$ Nozzle spray $\cdot$ Image processing

\section{Introduction}

Corona virus particles are spherical in shape with approximate diameters of 0.125 microns $(125 \mathrm{~nm})$. The smallest particles are of 0.06 micron size, whereas the largest are of

Dipankar Chatterjee

d_chatterjee@cmeri.res.in

1 CSIR-Central Mechanical Engineering Research Institute, Durgapur 713209, India
0.14 microns [1]. The virus is carried by the droplets released when someone coughs or sneezes and it remains viable, or able to still infect people, in aerosols for at least $3 \mathrm{~h}$ [2]. Additionally, it remains active on plastic and stainless steel surfaces for 2-3 days and remains infectious for up to $24 \mathrm{~h}$ on cardboard and $4 \mathrm{~h}$ on copper [2].

The term droplet is often taken to refer to droplets of size $>5 \mu \mathrm{m}$ in diameter that fall rapidly to the ground under gravity, and therefore they are transmitted only over a limited distance (e.g., $\leq 1 \mathrm{~m}$ ). On the contrary, the term droplet nuclei (or aerosol) refers to droplets having size $\leq 5 \mu \mathrm{m}$ in diameter that can remain suspended in air for significant periods of time, allowing them to be transmitted over distances $>1 \mathrm{~m} \mathrm{[3,4]}$. The droplet and aerosol motion depend significantly on various environmental factors, such as the gravity, the direction and strength of local airflows, local temperature and relative humidity (which will affect both the size and mass of the droplet due to evaporation).

Sneezing may produce as many as 40,000 droplets between $0.5-12 \mu \mathrm{m}$ in diameter $[5,6]$ that may be expelled at speeds up to $100 \mathrm{~m} / \mathrm{s}$ [7], whereas coughing may produce up to 3000 droplet nuclei, about the same number as talking for five minutes [8]. The novel corona virus can spread through the air-not just through the large droplets emitted in a cough or sneeze. Though current studies aren't conclusive, "the results of available studies are consistent with aerosolization of virus from normal breathing [9] ".

From the above discussion, it is clear that the virus can remain alive and active for quite a long on various surfaces and even some considerable time in air also under suspended condition. Hence, a person may get infected through all these various medium. Wearing a mask is of extreme importance in combating the infection under such situation. Another useful way to combat with the spreading of corona virus is proper sanitization and disinfection. A 
hand sanitization is an absolute necessity. Disinfection of various surfaces, rooms, etc., both indoor and outdoor may be taken up as a strong precautionary measure. The disinfectant most commonly used in outdoors is a diluted solution of sodium hypochlorite, or household bleach. These disinfectants may be useful for application over surfaces; however, its effectiveness on air-suspended aerosolized viruses is under research [10].

As a preventive measure to contain the spread of COVID-19, a tractor PTO (power take-off) powered outdoor disinfectant spray system is designed and developed. The tractor is attached with a tank having 12 nos. of spray atomization nozzles and 2 nos. of hand spray system (2 nozzles each) to deliver an aqueous disinfectant solution. There are several outdoor disinfectant fogger/ atomizer machines available in the market which are mainly carried by an operator and sprayed by hand. This mode not only requires great effort but also very much time-consuming. Additionally, the spray effect also cannot be guaranteed. Hence these are not suitable for long-distance operation. However, the current invention is capable of providing extensive operation with long stretches of highways.

Reference may be made to Patent no. WO2007085140A1 [11], wherein a disinfecting spray device comprising a liquid storage bottle and a spray head mounted on the mouth of the liquid storage bottle is described. It can be widely used for disinfection and deodorization in home, or in public places. However, the device is not suitable for long-distance operation since it is to be carried by an operator. In Patent no. CN203389122U [12], a disinfectant spraying vehicle is invented, which comprises a disinfectant solution sprinkling wagon, liquid storing barrel and shower nozzle. However, the device is specifically designed for disinfecting pig houses. Reference may be made to Patent no. US20120298151A1 [13], wherein a device for disinfecting, sterilizing and/or maintaining medical, especially dental, instruments is reported. From the above patent search, it is observed that there is no suitable device (or a vehicle) which can be extensively used for disinfecting large areas around long roads. Hence, the present invention could be an indispensable system under the current pandemic condition due to COVID-19 spread.

\section{Description of the Disinfectant Spray System}

The sanitizing unit designed and developed is driven by a tractor coupled with a normal liquid tank of capacity 2000-5000 L as shown in Fig. 1. The specific advantage of using a tractor is that it features a splined output shaft to which can be attached drive shafts to power implements. A live power take-off (PTO) transfers the power directly from the engine to the implement regardless of whether a tractor is moving or at rest. A high-pressure pump $\left(15-35 \mathrm{~kg} / \mathrm{cm}^{2}\right)$ is mounted at the rear side of the tractor on the designed base plate with proper support structure. The pump is driven by the power from the tractor PTO through belt pulley arrangement. The enhancement of the rotating speed of the pump is achieved by selecting suitable pulley ratio. The pump operates at its rated speed of $800-1400 \mathrm{rpm}$. The suction side of the pump is connected with the tank discharge port by flexible hose/MS pipes with ball valve. The pump discharge is connected with the discharge header through flexible hose. The discharge header is fabricated with 1 -inch pipe and is having four delivery pipes with ball valves. One delivery pipe is connected to the tank mounted piping network, and two other delivery pipes are supplying pressurized liquid to the hand sprayer through flexible hose. The remaining delivery pipe is for draining the excess amount of liquid. The spray piping network is attached as an embodiment around the liquid containing tank involving twelve numbers of mist nozzles placed at a gap spacing of $500 \mathrm{~mm}$. The nozzles are arranged in such a way that as the tractor moves a maximum possible area may be covered by the nozzles. There is also a provision of two hand spraying systems which can be extendable up to 30 feet on both sides of the vehicle. Each hand spraying system is attached with two mist nozzles at their delivery end. The hand sprayers are provided in order to reach certain places where the tractor may not be able to enter.

A liver operated mechanism helps in engagement/disengagement of the tractor with the system. Opening/closing of the valves at different locations allows a synchronized liquid flow through the network. The spray can be accomplished either in the form of mist or jet by adjusting a rotating knob in the nozzle. The tank is attached with the tractor by universal coupling, thereby eliminating difficulties during turning of the vehicle. Figure 2 demonstrates the sanitizing unit under operation for disinfection of road side.

\section{Materials, Methods and Discussion}

In order to determine the effectiveness of a spraying system in an objective and quantitative manner, a systematic analysis may be performed either through an experimental route or by numerical simulation. Certain characteristics of a spray such as the cone of the spray, length of penetration, wettability/impact, etc., can be estimated to understand its effectiveness. An image processing technique is utilized here to perform the effectiveness analysis of the nozzle spray. To start with, spray from a single nozzle of the system is analyzed keeping the other nozzles closed. Laser sheet is generated by a double-pulsed Nd:YAG laser 
Fig. 1 3-D CAD model of the tractor-driven sanitizer unit a side view, b top view

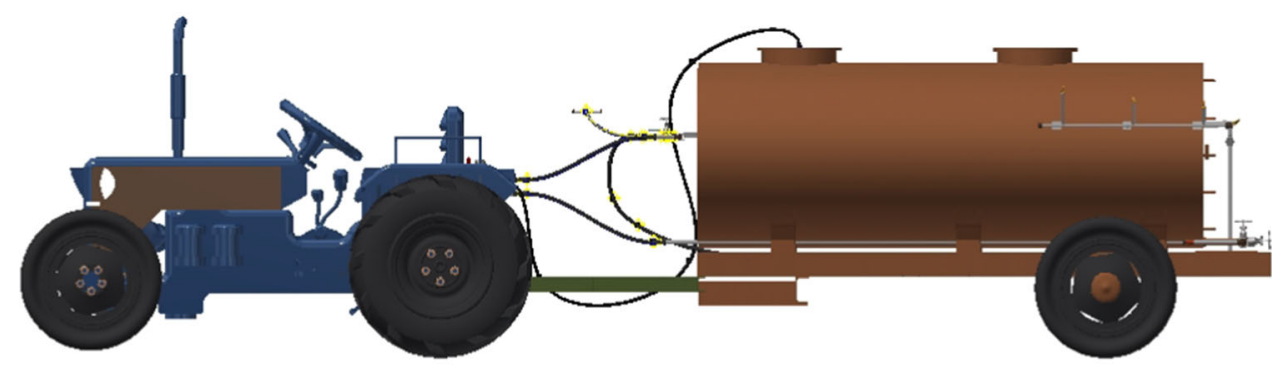

(a)

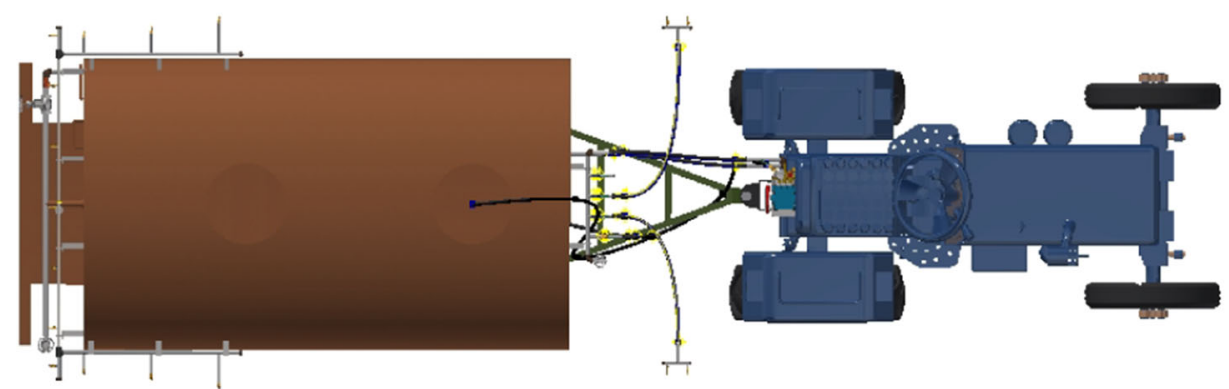

(b)

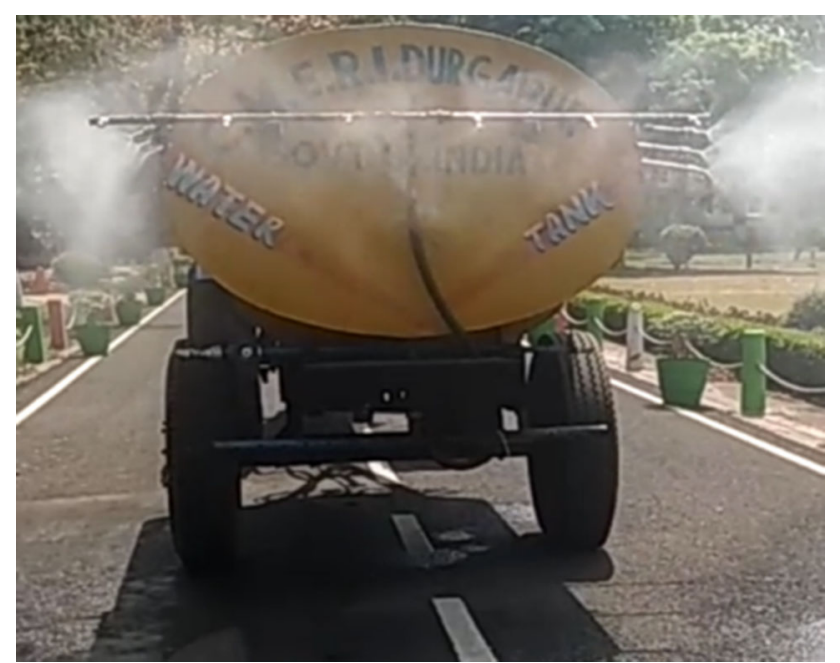

Fig. 2 Road sanitizing unit under operation

manufactured by QUANTEL, France [14]. Laser source was kept at different distances such as $1 \mathrm{~m}, 2 \mathrm{~m}$ and $3 \mathrm{~m}$ from the nozzle, and the laser light was kept perpendicular to the spray direction so that the total plane of spraying can be visible. The schematic diagram of experimental setup is shown in Fig. 3.

The plane of the jet at $1 \mathrm{~m}$ distance was acquired via a DSLR camera (Nikon D3300) in video mode with ISO $3200,300 \mathrm{~mm}$ focal length and 50 frames per second. Synchronization of laser and camera is done using a nanosecond timer box controlled by TSI $4 \mathrm{G}$ imaging software [15]. TSI 4G imaging software installed on a DELL PRECISION T7600 workstation coordinates the whole flow visualizations. After acquiring the movie, 2630 nos. of frames were extracted from $50 \mathrm{~s}$ duration video file, where the frame resolution was 1920 X1080 pixels. However, due to mismatch of acquiring frequency and laser frequency, all the frames were not useful, so only frames having full frame illumination were selected for processing. This way, total 195 frames were selected for image processing and feature extraction.

The image processing operation was performed in MATLAB $2014^{\mathrm{TM}}$ environment with necessary functions. The image from the front plane was preprocessed, where the blue channel matrix was extracted from the selected color images. However, the green channel should be extracted as the used laser was green in color [16]. But, that was over-saturated, so most of the pixels became 255 gray value; accordingly, the blue channel was extracted. The acquired and pre-processed images are shown in Fig. 4a, b, respectively.

It can be seen from Fig. $4 \mathrm{~b}$ that the plane of the jet looks quasi-circular and irregular. The lower quarter portion of the image can be approximated for the evaluation of total circular area and the area of influence. Accordingly, the lower quarter image has been cropped (Fig. 5a) and from that the circular portion of jet coverage has been extracted (Fig. 5b).

Therefore, the extracted coverage area was selected by trial and error and the area with a circle of 360 pixel radius has been selected. After that, the extracted portion was thresholded by using Otsu's optimal thresholding method [17] as shown in Fig. 6.

After thresholding the area having pixel value 1 (i.e., coverage area) was determined to evaluate the one-fourth 

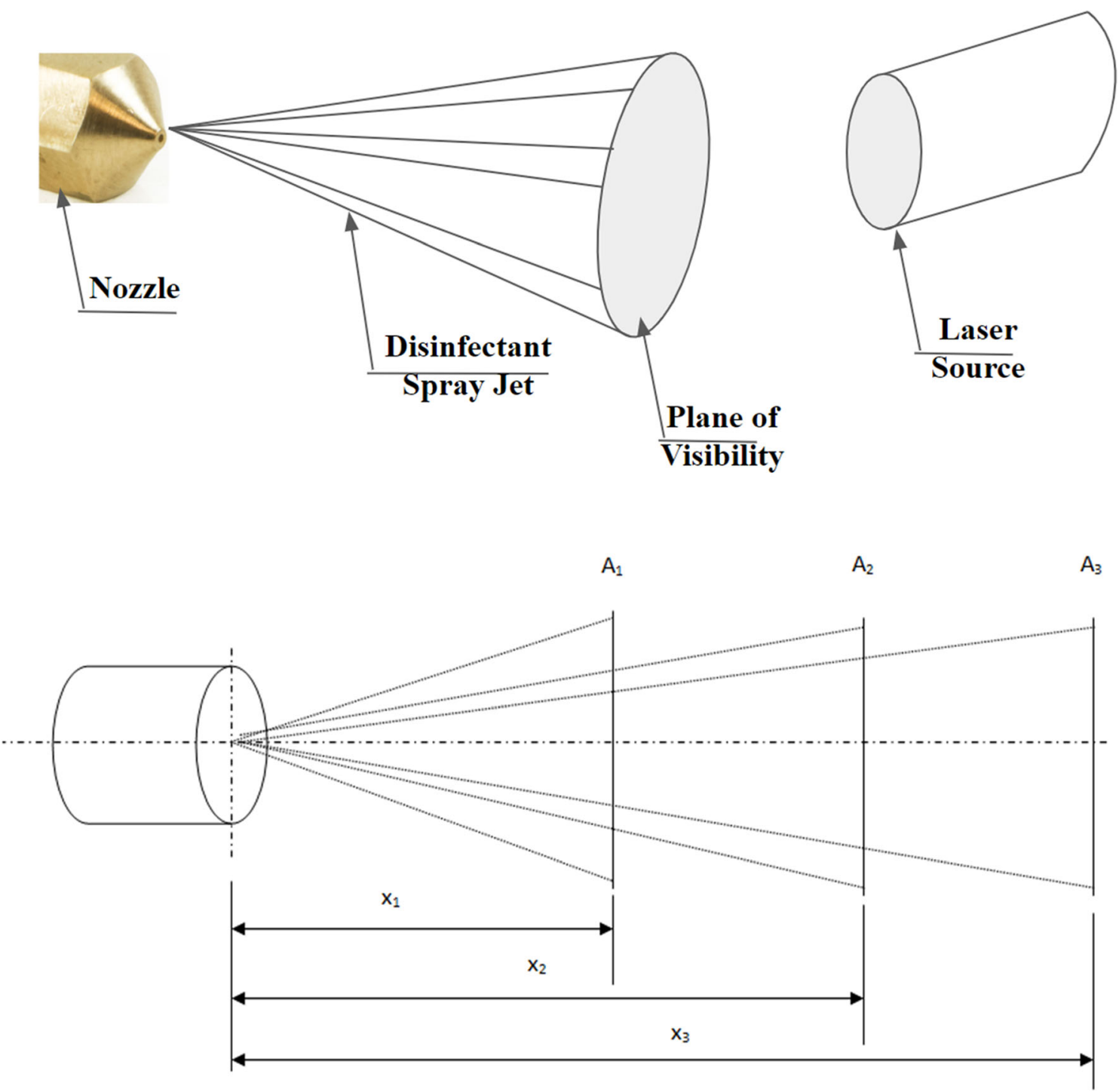

Fig. 3 Schematic of the experimental setup

Fig. 4 a Original RGB image and $\mathbf{b}$ extracted blue channel

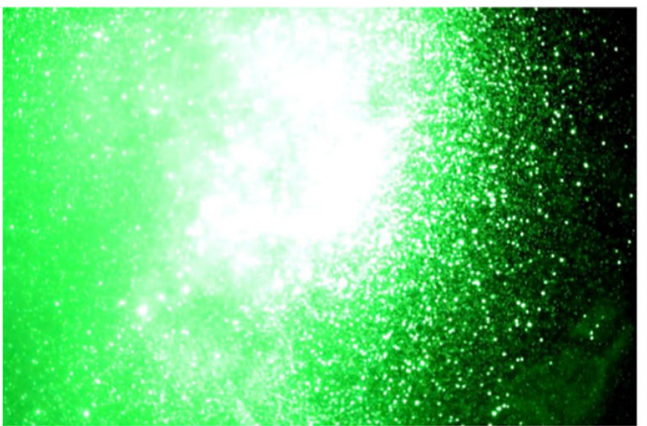

(a)

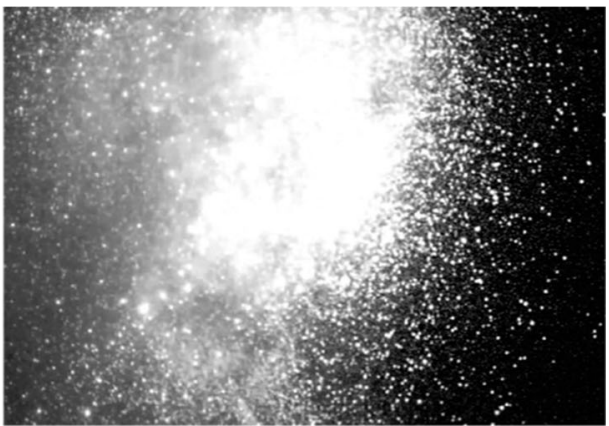

(b) of the area of influence. Finally, the fraction of area of influence was determined by using the following equation:

Area of influence (in fraction)

$=$ coverage area/area of quarter circle
In order to determine the droplet size, edge detection operation (Canny edge detection) [18] has been performed on the thresholded images of Fig. 5a. Then, circle Hough transform (CHT) operation has been performed to 
Fig. 5 a Lower quarter portion of jet and $\mathbf{b}$ extracted portion as coverage area

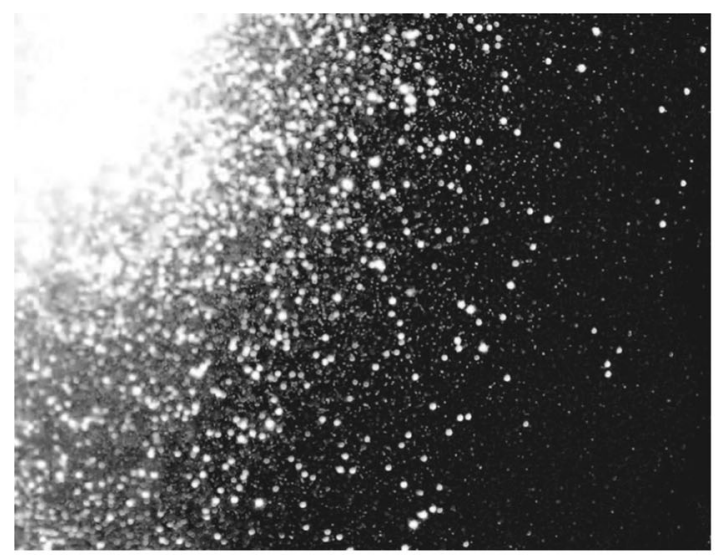

(a)

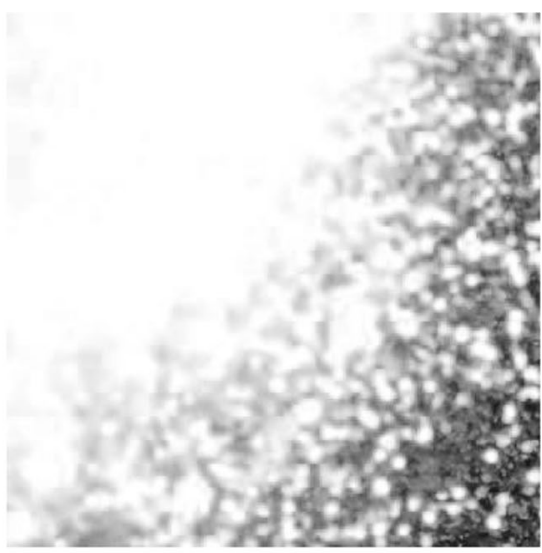

(b)

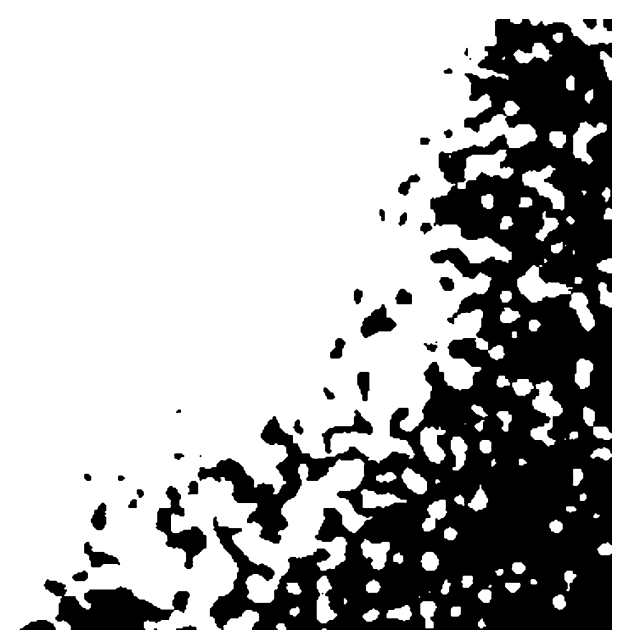

Fig. 6 Thresholded image of Fig. 4b

determine the average droplet diameter [19-21]. The image of CHT is shown in Fig. 7.

In this case, the average diameter estimated was $3.52 \mathrm{~mm}$ with $0.05 \mathrm{~mm}$ standard deviation over 195 images.

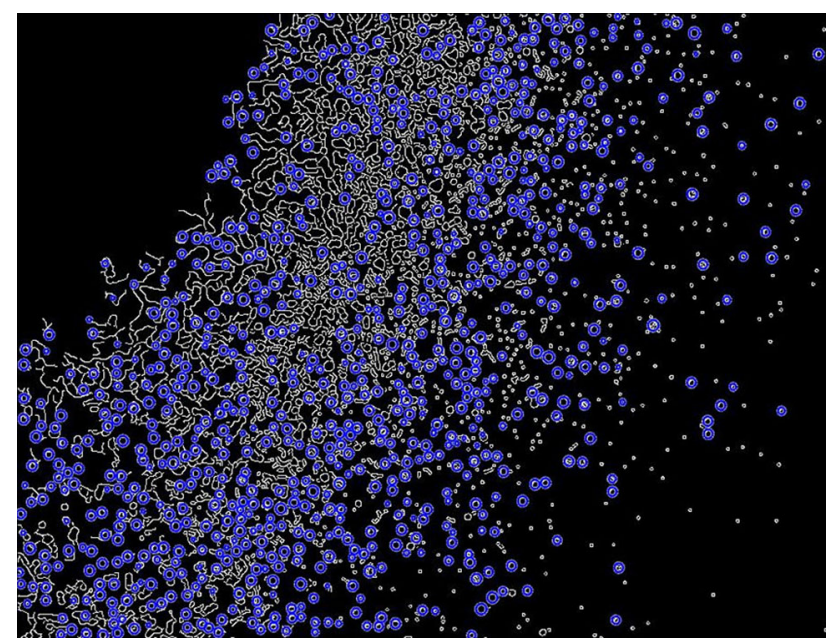

Fig. 7 CHT of Fig. 5a
In a similar manner, droplet size (with standard deviation) and the area of influence were determined for other axial distances which are summarized in Table 1:

Figure 8 shows the droplet size and area of influence variations with axial distance from the nozzle. A statistical curve fitting with an exponential fit is performed. The fit functions are shown in the figures with best fit values of the coefficients. The goodness of the fit can be understood from the errors as given below:

$$
\begin{aligned}
{\left[\varepsilon\left(d_{0}\right)\right.} & =0.0019, \varepsilon(\delta)=0.256, \varepsilon(\gamma)=0.0023 ; \varepsilon\left(I_{0}\right) \\
& =0.0012, \varepsilon(\alpha)=2.89, \varepsilon(\beta)=0.0002]
\end{aligned}
$$

\section{Summary}

A tractor powered disinfectant spray system is designed and developed for the containment of COVID-19 spread. The sanitizing unit is specifically useful for long road sanitization in addition to narrow lane, market place, etc., with the hand sprayer system. Since the liquid tank is attached with the tractor there is no need for any additional power source to drive the tank. Also, the pump circulating the liquid is powered from the tractor PTO.

An image processing technique is applied to estimate the effectiveness of the disinfectant spray system. The effectiveness of the system is quantified and measured in the form of average droplet size of the spray and its area of influence. However, no such claim has been made in this study that the system could be able to destroy or kill corona virus. Overall, it is observed that the droplets are larger in size close to the spray nozzle and the size decreases as the

Table 1 Droplet size and area of influence at different axial distances

\begin{tabular}{lll}
\hline Distances & Droplet size & Area of influence $(\%)$ \\
\hline $1 \mathrm{~m}$ & $3.52 \mathrm{~mm}(\mathrm{SD} 0.345 \mathrm{~mm})$ & 87 \\
$2 \mathrm{~m}$ & $1.89 \mathrm{~mm}(\mathrm{SD} 0.201 \mathrm{~mm})$ & 39 \\
$3 \mathrm{~m}$ & $1.47 \mathrm{~mm}(\mathrm{SD} 0.174 \mathrm{~mm})$ & 20 \\
\hline
\end{tabular}




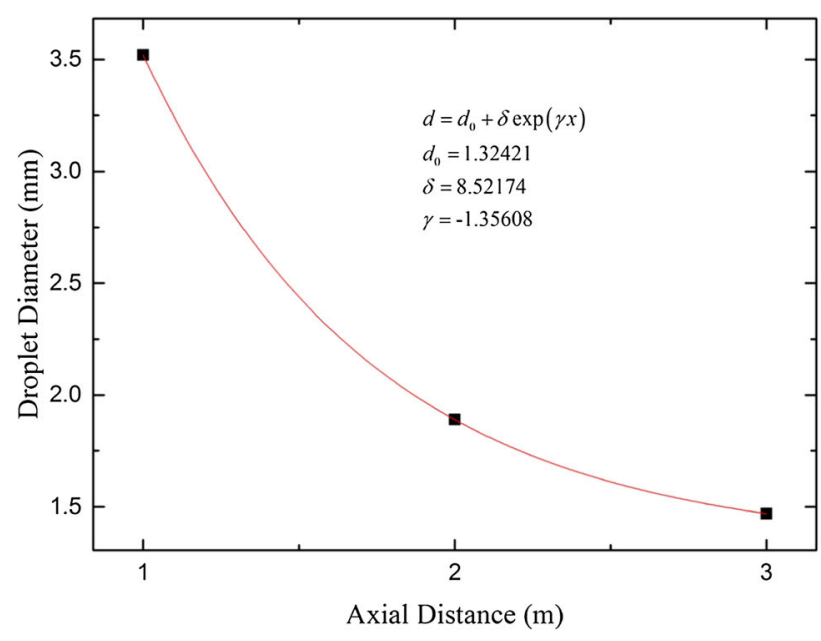

(a)

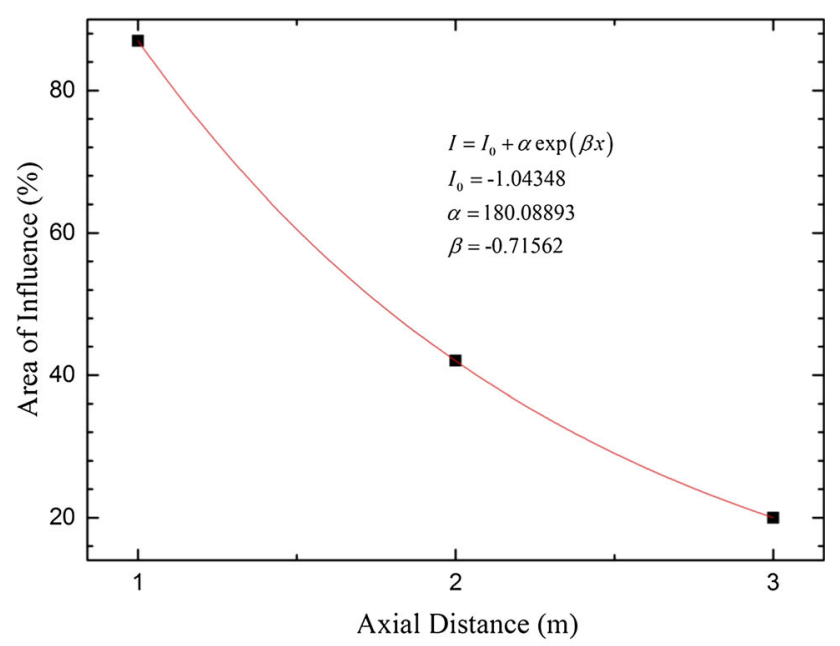

(b)

Fig. 8 a Droplet size and $\mathbf{b}$ area of influence variations with axial distance from nozzle

axial distance increases in an exponential fashion. Accordingly, the area of influence, i.e., the effectiveness of the spray system, is more near the nozzle with an estimated efficiency of $87 \%$ and decays exponentially with the axial distance. This is because of the fact that as the axial distance from the nozzle increases, the spray gets more diffused and driven away from the target due to turbulent diffusion. Hence, the striking effectiveness of the spray on a specific target decreases with increasing distance.

\section{References}

1. Cynthia S. Goldsmith et al., Ultrastructural characterization of SARS coronavirus. Emerg. Infect Dis. 10(2), 320-326 (2004). https://doi.org/10.3201/eid1002.030913
2. N. van Doremalen et al., Aerosol and surface stability of SARSCoV-2 and compared it with SARS-CoV-1. N. Engl. J. Med. 382, 1564-1567 (2020). https://doi.org/10.1056/NEJMc2004973

3. L.D. Stetzenbach, M.P. Buttner, P. Cruz, Detection and enumeration of airborne biocontaminants. Curr. Opin. Biotechnol. 15(3), 170-174 (2004). https://doi.org/10.1016/j.copbio. 2004.04.009

4. K.C. Wong, K.S. Leung, Transmission and prevention of occupational infections in orthopaedic surgeons. J. Bone Joint Surg. Am. 86(5), 1065-1076 (2004). https://doi.org/10.2106/00004 623-200405000-00029

5. E.C. Cole, C.E. Cook, Characterization of infectious aerosols in health care facilities: an aid to effective engineering controls and preventive strategies. Am. J. Infect. Control 26(4), 453-464 (1998). https://doi.org/10.1016/s0196-6553(98)70046-x

6. J.W. Tang et al., Factors involved in the aerosol transmission of infection and control of ventilation in healthcare premises. J. Hosp. Infect. 64(2), 100-114 (2006). https://doi.org/ 10.1016/j.jhin.2006.05.022

7. W.F. Wells, Airborne Contagion and Air Hygiene (Harvard University Press, Cambridge, 1955)

8. D. Fitzgerald, D.W. Haas, Mycobacterium tuberculosis, in Principles and Practice of Infectious Diseases, 6th edn., ed. by G.L. Mandell, J.E. Bennett, R. Dolin (Churchill Livingstone, Philadelphia, 2005)

9. https://www.sciencemag.org/news/2020/04/you-may-be-able-spre ad-coronavirus-just-breathing-new-report-finds

10. https://www.sciencemag.org/news/2020/03/does-disinfectingsurfaces-really-prevent-spread-coronavirus\#

11. A disinfecting spray device, Patent no. WO2007085140A1, WIPO (PCT), 2006

12. Disinfectant spraying vehicle, Patent no. CN203389122U, China, 2013

13. Device for disinfecting, sterilizing and/or maintaining medical, especially dental, instruments, Patent no. US20120298151A1, United States, 2011

14. Quantel. Evergreen big laser series, 2007

15. TSI. Model 610036 LASERPULSETM synchronizer operation and service manual, 2011

16. R.C. Gonzalez, R.E. Woods, S.L. Eddins, Digital Image Processing Using MATLAB (Pearson Education India, Bengaluru, 2004)

17. N. Otsu, A threshold selection method from gray-level histograms. IEEE Trans. Syst. Man Cybern. 9(1), 62-66 (1979). https://doi.org/10.1109/TSMC.1979.4310076

18. L. Ding, A. Goshtasby, On the Canny edge detector. Pattern Recogn. 34, 721-725 (2001)

19. S.J.K. Pedersen, Circular hough transform, Aalborg University, Vision, Graphics, and Interactive Systems, 123 (2007)

20. W.W.M. Khairosfaizal, A.J. Nor'aini, Eyes detection in facial images using circular hough transform, in 5th International Colloquium on Signal Processing \& Its Applications, IEEE, pp. 238-242 (2009). https://doi.org/10.1109/cspa.2009.5069224

21. N. Cherabit, F.Z. Chelali, A. Djeradi, Circular hough transform for Iris localization. Sci. Technol. 2(5), 114-121 (2012). https://doi.org/10.5923/j.scit.20120205.02

Publisher's Note Springer Nature remains neutral with regard to jurisdictional claims in published maps and institutional affiliations. 